Research Paper

\title{
PSA and Prostate Health Index based prostate cancer screening in a hereditary migration complicated population: implications in precision diagnosis
}

\author{
Mariyam Akizhanova ${ }^{1 *}$, Elzira E. Iskakova ${ }^{2 *}$, Valdemir Kim ${ }^{1 *}$, Xiao Wang ${ }^{3}$, Roman Kogay1\#, Aiym \\ Turebayeva1\#, Qinglei Sun ${ }^{3}$, Ting Zheng 3 , Shenghui $\mathrm{Wu}^{4}$, Lixia Miao ${ }^{5}$ and Yingqiu Xie ${ }^{1 凶}$ \\ 1. Department of Biology, School of Science and Technology, Nazarbayev University, Astana, 010000, Republic of Kazakhstan; \\ 2. Module of Pathological Anatomy, Kazakh National Medical University, Almaty, 050000, Republic of Kazakhstan; \\ 3. Shandong Analysis and Test Center, Shandong Academy of Sciences, 19 keyuan Street, Jinan, 250014, P.R. China; \\ 4. Department of Epidemiology \& Biostatistics, University of Texas Health at San Antonio Laredo Campus, Laredo, TX 78041, USA; \\ 5. College of Basic Medicine, Wuhan University, Wuhan, 430071, P.R. China. \\ * Co-first authors \\ \# Contributed equally \\ $\triangle$ Corresponding author: Dr. Yingqiu Xie, Department of Biology, Nazarbayev University, School of Science and Technology, 53 Kabanbay Batyr Ave., Astana, \\ 010000, Republic of Kazakhstan Phone: +7 7172704686 Email: xieautumnus@yahoo.com \\ (c) Ivyspring International Publisher. This is an open access article distributed under the terms of the Creative Commons Attribution (CC BY-NC) license \\ (https://creativecommons.org/licenses/by-nc/4.0/). See http://ivyspring.com/terms for full terms and conditions.
}

Received: 2016.10.22; Accepted: 2016.12.23; Published: 2017.04.10

\begin{abstract}
Precision diagnosis requires specific markers for differential ethnic populations. Prostate-Specific Antigen (PSA) level (threshold of $4 \mathrm{ng} / \mathrm{ml}$ ) has been widely used to screen prostate cancer and as reference of pro-biopsy but false diagnosis frequently occurs. Prostate health Index (PHI) is a new diagnosis marker which combines PSA, free PSA and P2PSA4. Overall the PCa screening database is lacking in Kazakhstani patients. We analyzed the PSA levels and Gleason scores of 222 biopsies collected in 2015 in Almaty area, Kazakhstan approved by institutional ethics board. We found using PSA of $4 \mathrm{ng} / \mathrm{ml}$ as threshold, only $25.68 \%$ of patients have cancer with Gleason score ranged 6-8 and $65.77 \%$ of patients have no character of cancer. Moreover, there is no significant correlation between PSA and cancerous $(P=0.266)$ or Gleason grade $(P=0.3046)$ based on pathological biopsy. In addition, $\mathrm{PHI}$ is not correlated to prostate cancer $(\mathrm{P}=0.4301)$. Our data suggest that false-positive rate is much higher than the correct-positive diagnosis when using PSA as the first screening. Thus in this cohort study, most patients can not get benefit from the PSA screening for precision PCa diagnosis. As Kazakhstani family trees are unique and complicated because of history and migration, the high rate of over diagnosis might be due to the hyperexpression of PSA via heterosis in Eurasian men. Therefore we should be cautious when using pro-biopsy in precision diagnosis for Eurasian prostate cancer patients.
\end{abstract}

Key words: PSA, prostate cancer, precision medicine, diagnosis.

\section{Introduction}

Prostate cancer (PCa) is one of the most prevalent and frequently diagnosed cancers among male all over the world. It is expected that number of cases will be increased to 1.7 million approximately by the year of 2030 [1]. These figures can be explained by the overall aging of population, which contributes to some of the risk factors. The other factors are family history of PCa patients and ethnicity. In particular, the incidence has dramatically increased over the past decade in Asian males [2-3]. Asian countries have been reported to have considerably lower incidence rate compared to African Americans and European Caucasians [2]. However, recent data showed general trend towards increasing mortality rate in Asia in 
particular in China (Hong Kong), Kazakhstan, and Korea, even faster than in high-risk countries due to changes in the lifestyle, westernization of diet and increase of obesity [3-5].

Personalized medicine is able to predict the onset of the disease at an early stage and, more importantly, enables health care system to function more efficiently. Patients have an opportunity to benefit from major discoveries in biology and Human Genome Project. Personalized medicine has been applied into diagnosis of PCa. One of the valuable preventive clinical tools for $\mathrm{PCa}$ is early screening using serum for detection of prostate specific antigen testing (PSA). PSA is a serine protease produced by both malignant and normal cells [6]. In healthy organism prostate specific antigen is secreted into glandular ducts in concentrations million times higher than in plasma but in PCa, malignancy causes damage to secretory pathways which allow leaking of PSA into extracellular space [6]. Therefore, increased PSA level in serum is a sign of both inflammatory and neoplastic processes happening in prostate. There are many debates on PSA screening accuracy. Moreover, the correlation between PSA and PCa measured by Gleason Score is still unclear in different populations [7]. Another method to measure PSA is prostate health Index (PHI) which combines PSA, free PSA and p2PSA4 [8]. Compared to traditional PSA method, PHI based screening accuracy remains elusive.

Kazakhstan is one of the Asian countries where prostate cancer became a serious health concern due to increase in incidence and mortality [3-5]. In 2006 there were 606 cases per 100000 with more than 50\% mortality rate [3-5]. National census (2009) revealed that Kazakhstani population constitutes over 17 million people [9]. Among them only $63.1 \%$ are ethnic Kazakhs, 23.7\% are Russians and others are Uzbeks, Germans, Tatars, Azerbaijanis, Ukrainians etc [9]. Therefore it is extremely important to personalize medicine for prostate cancer diagnosis in Kazakhstan. The first attempt was performed in 2015 when "Personalized medicine and Global Health" conference was held in Astana organized by the Nazarbayev University. However, area of personalized medicine is still poorly developed. As a result, there is a lack of reliable prostate cancer screening system in Kazakhstan.

Widely accepted threshold value of PSA for Western countries is $4.0 \mathrm{ng} / \mathrm{ml}$ [10]. Patients are strongly recommended to perform biopsy to verify or exclude presence of PCa if the value is higher than the threshold. However, this particular cut-off value is not uniform across the ethnicities. Recent studies reported that Asian people with PSA less than 4.0 $\mathrm{ng} / \mathrm{ml}$ also have a high positive predictive PCa [11].
Taking into account of multinationalism and high number of interethnic marriages during last 8 centuries it is suggested that PSA cut-off values of neither Asians nor Europeans are applicable for Kazakh population [12]. Absence of extensive screening, specific to Kazakhstan cut-off value of PSA and imperfections of PSA based method itself are major burdens in development of reliable testing system for prostate cancer. There is a high demand in search for new accurate methods for PCa prediction which are personalized for Kazakhstani population with its specific phenotype.

\section{Materials and methods}

\section{Patients}

The study was conducted according to the approval of Kazakh National Medical University ethical board. PSA diagnosis results of 222 Kazakhstani male cancer patients aged between 50 and 66 were used in this study, which was held in 2015 at Almaty Medical Center, Kazakhstan. This Center has served a large quantity of local and national population for a long period of time using invariable methods. These results gave a possibility to use PSA levels and Gleason score to study the standards of PSA diagnosis in Eurasian men, particularly men from Kazakhstan. Blood samples were taken from these men and the concentrations of total, free PSA and p2PSA in units of $\mathrm{ng} / \mathrm{ml}$ were measured. The techniques of obtaining PSA serum were the same for all patients. PSA was measured within a week after getting the blood sample. Biopsy was done after the PSA diagnosis test for all of the patients. The results of pathological biopsy were also used for identification of Gleason score. Gleason score was needed for determination of PSA diagnosis accuracy, differentiating the patients with cancer from patients with false positive PSA test results. A pathologist assigned the score and the variables such as age and prior medical history were hidden from the specialist. Finally, the diagnosis was approved by positive results of biopsy and an urologist conclusion.

\section{Statistical calculation}

A special document for collecting all of the needed information on variables and the test results of each patient was created. Given that all continuous variables abnormally distributed, non-parametric analysis was done on the number of patients with higher and lower PSA levels than standard. The quantity of patients with PSA more or less than 4 $\mathrm{ng} / \mathrm{ml}$, was calculated and illustrated on the histogram. Moreover, patients with cancer and without cancer, according to their biopsy results, were shown in both categories. The same was done in the 
means of PHI testing method for the comparison of tests. The accuracy of both tests was determined by checking the correlation using Chi-square analysis. The distribution of PSA level and Gleason score of each patient was analyzed and the statistical significance was determined according to the Spearman's correlation test. Number of patients with false positive results was also calculated to visualize low correlation of PSA level diagnosis, PHI testing with the actual cases of prostate cancer.

\section{Results}

We collected data of 222 male patients aged 50-66 upon ethics board approval at Kazakh National Medical University to compare PSA levels and Gleason score from biopsy in 2015 in Almaty area, Kazakhstan. The overall data representation is shown in the Figure 1A. In this cohort study, cancer prediction by using PSA level of $4 \mathrm{ng} / \mathrm{ml}$ as threshold resulted in high amounts of false positive (146 patients out of 146+57). It means that out of 203 patients with expected prostate cancer, only 57 of them will have the disease. Thus only low percentage (7.66\%) of correct negative patients with PSA levels ranging from 1.7 to $3.9 \mathrm{ng} / \mathrm{ml}$ showed no pathological characteristics of prostate cancer or just prostatic intraepithelial neoplasia (PIN) (Fig. 1A). On the contrary, for those with higher levels of PSA than $4 \mathrm{ng} / \mathrm{ml}$, only $25.68 \%$ patients have cancer with Gleason score ranging from 6-8 and majority of patients $(65.77 \%)$ have no character of cancer or just PIN. Moreover, very few patients $(0.9 \%)$ showed PSA less than $4 \mathrm{ng} / \mathrm{ml}$ but with cancer. Our data suggest that false positive rate is much higher than the correct positive diagnosis rate using PSA as the first screening. In this cohort study, only about one fourth patients can get benefit from the PSA screening to predicate the cancer which is consistent with the Gleason grade detection (Fig.1B). PHI is also not correlated to cancer $(\mathrm{P}=0.4301)$ (Fig.1C). Furthermore, there is no significant correlation between PSA and cancerous $(P=0.266)$ or Gleason grade $(P=0.3046)$ confirmed by pathological biopsy (Fig.1D) even there is a Spearman's correlation if based on rank of specific range of values. Namely, there is a non-linear similar trend between PSA levels of 4-35 ng/ $\mathrm{ml}$ and Gleason score of 6-7 in Kazakhstani cancer patients $(\mathrm{N}=222)$ (Fig.1D).

Next, we found the test sensitivity is high as $96.61 \%$, but along with it, its specificity is at a very low level as $10.43 \%$. This analysis suggests that, probably, for Eurasian, or old, or both groups of male the threshold of PSA for cancer prediction should be higher in order to increase the specificity. The summary is shown in the Table 1.
Table 1. Comparison of the results of PSA test with prostate cancer status

\begin{tabular}{llll}
\hline PSA Test results & \multicolumn{3}{l}{ True characteristics in 222 subjects } \\
\cline { 2 - 4 } & True "Cancer" & True "No Cancer" & Class precision \\
\hline $\begin{array}{l}\text { Pred. “Cancer" } \\
\text { (PSA } \geq 4 \text { ) }\end{array}$ & 57 & 146 & $28.08 \%$ \\
$\begin{array}{l}\text { Pred. "No Cancer" } \\
\text { (PSA }<4 \text { ) }\end{array}$ & 2 & 17 & $89.47 \%$ \\
Class recall & $96.61 \%$ & $10.43 \%$ & \\
\hline
\end{tabular}

For statistical analysis "Reference Value Advisor V2.1" software [13] was used. The overall data analysis of PSA level in patients have shown that there is a correlation between high PSA level and cancer at higher values, but at lower levels, the correlation is almost negligible. The distribution of PSA level in healthy and cancer-positive patients confirms the absence of correlation, by showing high similarity. The distributions are shown in the Figure 2. The reference value estimation confirmed this assumption. The results are shown in Table 2.

Moreover, as shown in Figure 3, there is no significant correlation between age and PSA levels, suggesting that PSA levels are not dependent on age.

Table 2. Statistical analysis on PSA levels in different types of patients

\begin{tabular}{lll}
\hline & "Cancer" & "No cancer" \\
\hline Mean $(\mathrm{ng} / \mathrm{mL})$ & 18.5 & 8.2 \\
Median $(\mathrm{ng} / \mathrm{mL})$ & 8,2 & 6.0 \\
Minimum value $(\mathrm{ng} / \mathrm{mL})$ & 3.14 & 1.7 \\
Maximum value $(\mathrm{ng} / \mathrm{mL})$ & 100 & 91.5 \\
Reference interval $(\mathrm{ng} / \mathrm{mL})$ & $3.5-100$ & $3.1-31.4$ \\
\hline
\end{tabular}

\section{Discussion}

The cohort study suggests that both PSA and PHI have poor correlation with the PCa prediction in Eurasian men. PSA test remains to be one of most wide spread and controversial diagnostics marker for PCa. According to the American Cancer Society, PSA level above $4 \mathrm{ng} / \mathrm{mL}$ and below $10 \mathrm{ng} / \mathrm{mL}$ have $25 \%$ chance of PCa occurrence and PSA level more than 10 $\mathrm{ng} / \mathrm{mL}$ increases chances of PCa occurrence over $50 \%$ [14]. Our study confirms its inaccuracy of false-positive and false-negative predictions. Even in European Randomized Study of Screening for Prostate Cancer (ERSPC) including 162,387 men PSA test showed $75.9 \%$ false-positive results [15]. Such a high false prediction rate can be explained by several factors. For example, enlarged prostate gland such as benign prostatic hyperplasia $(\mathrm{BPH})$ may lead to the increase in PSA level, but no cancer was detected [16]. Moreover, PSA level is higher with older age [17]. In addition, High BMI decreases PSA level [18] and 
Prostatitis increases PSA level [19]. Ambulation, ejaculation can also affect PSA level [20]. In order to make accurate diagnosis, all factors should be counted and PSA test results have to be adjusted. From our results it can be seen that PSA test model needs improvements. For example, PSA levels between 2.5 and $10 \mathrm{ng} / \mathrm{mL}$ and low urinary PSA levels are associated with PCa [21]. Along with PSA test and its variations, there are several alternative diagnostics markers developing nowadays. These include Insulin-like growth factor-1 (IGF-1), Transforming growth factor- $\beta 1$ (TGF- $\beta 1$ ), Early prostate cancer antigen (EPCA), Anterior gradient 2 (AGR2), Prostate cancer antigen 3 (PCA3) [22-26]. However, reliability of these systems varies and is still under investigation.
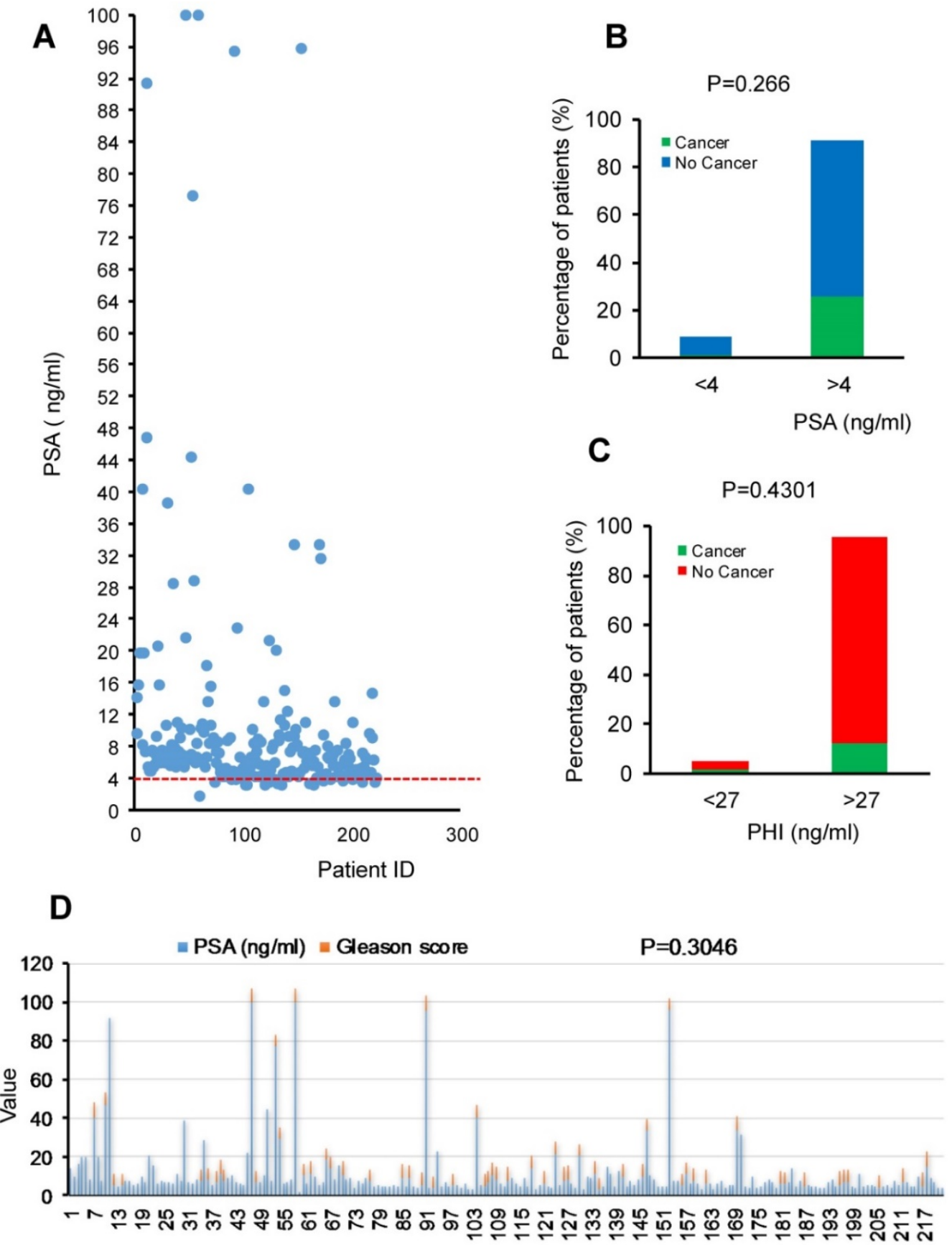

Patient ID

Figure 1. Levels of PSA, PHI, and Gleason grade of prostate cancer patients from Kazakhstan. A. The distribution of PSA in Kazakhstani patients of the cohort study. B. The percentage of patients with different levels of PSA $(<4 \mathrm{ng} / \mathrm{ml}$ and $>4 \mathrm{ng} / \mathrm{ml})$ or PHI $(<27 \mathrm{ng} / \mathrm{ml}$ and $>27 \mathrm{ng} / \mathrm{ml})$. C. Chi-square analysis showed the $P$ value. D. The distribution of PSA and Gleason score in prostate cancer patients in the cohort study. Spearman's correlation analysis showed the $P$ value is 0.3046. 

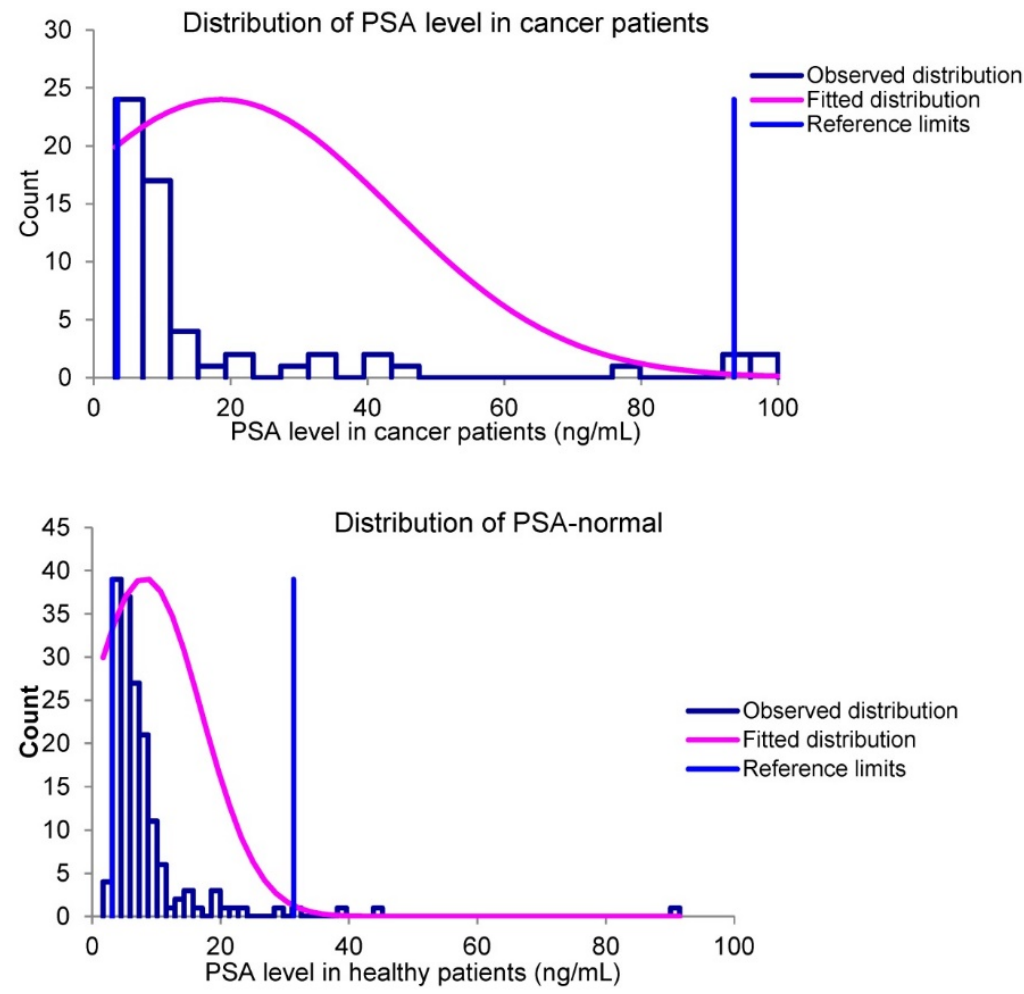

Figure 2. PSA levels distribution in cancer and healthy patients

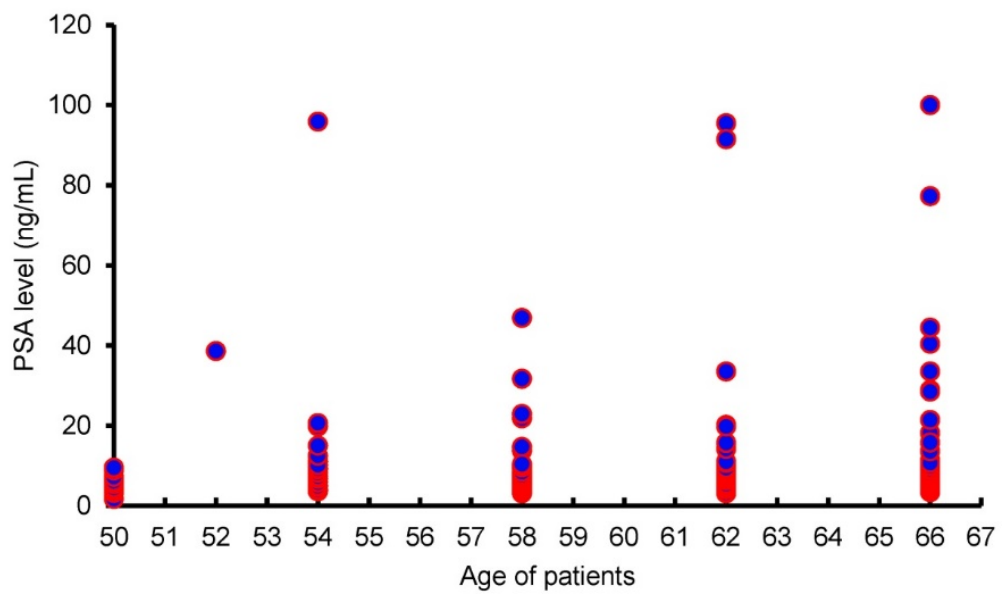

Figure 3. Distribution of PSA levels in different ages

There is a low correlation between cancer incidence and widely accepted PSA cut-off value. For biochemical reason, Esther et al. reveals that there is another method based on determination of PSA glycosylation-specific abnormalities or changes [27]. Oncogenic processes may highly influence cellular glycosylation process and PSA has carbohydrate content so it is predicted that glycosylation involves alteration of gene expression and activity of glycosyltransferases [16]. One more approach of early detection of $\mathrm{PCa}$ using non-invasive way is to measure non-coding RNA, miRNA level in patients' blood [28]. It has been shown that in PCa and BPH patients, seven miRNAs such as miR-675 levels were significantly altered in cancer and non-cancer groups [28].

From our data we found some abnormal cases that super high values of PSA but not related to cancer. The reason for high value of PSA might be the hyperexpression of PSA by hybrid vigor in Eurasian men but may not necessarily by cancer. According to Ayagan (2013) from 1st to 6th century the Great Steppes were inhabited by different nomadic tribes such as Huns, Avars with further formation of Turkic Khaganate [12]. All of the mentioned stages created unique phenotype of population which is different from other Asians such as Chinese, Koreans, and Japanese [12]. Thus further genetic testing to study the 
correlation of PSA gene locus heterogeneity and PCa would uncover the new mechanism of PSA alterations in Kazakhstani patients.

\section{Conclusion}

PSA screening is currently used diagnostic test for predicting prostate cancer in Kazakhstan. The results of this study showed that PSA test is not a reliable method for determining PCa in Kazakhstani patients. There was a high trend of false-positive results for this test, so it gave rather negative impact because of unnecessary biopsies. The low correlation with cancer was mostly seen in the patients with lower PSA levels. Moreover, PHI test, which is the combination of several types of PSA (overall PSA, free PSA, p2PSA) measurements, was tested for the accuracy as an alternative diagnostic tool. However, this test also did not show the high correlation of the diagnostic test and the PCa. Future suggestions are to discover and use other markers such as glycosylation pattern and specific miRNA levels. Novel PCa diagnostics markers are urgently needed to increase the quality of personalized medicine in Kazakhstan.

\section{Acknowledgements}

The research is supported in part by starting package to Yingqiu Xie, Kazakhstan-China collaboration grant, and China-Kazakhstan collaboration grant (No. CK-07-09) to Yingqiu Xie and Lixia Miao. We would like to thank the Department of Biology, SST, and Nazarbayev University for the support of flipped teaching and learning, research combined teaching innovations of Junior Research Seminar and Biochemistry I courses for undergraduate students. The authors would like to thank all the Junior Research Seminar and Biochemistry I courses students of Nazarbayev University for their support for the publication of their assignment for this paper.

\section{Competing Interests}

The authors have declared that no competing interest exists.

\section{References}

1. Haas GP, Delongchamps N, Brawley OW, Wang CY, de la Roza G. The worldwide epidemiology of prostate cancer: perspectives from autopsy studies. Can J Urol. 2008 ;15(1):3866-71.

2. Kimura T. East meets West: ethnic differences in prostate cancer epidemiology between East Asians and Caucasians. Chin J Cancer. 2012;31(9):421-9.

3. Pakzad R, Mohammadian-Hafshejani A, Ghoncheh M, Pakzad I, Salehiniya H. The incidence and mortality of prostate cancer and its relationship with development in Asia. Prostate Int. 2015; 3(4):135-40.

4. Chen R., Ren S., Yiu MK., et al. Prostate cancer in Asia: a collaborative report. Asian Journal of Urology, 2014;1(1): 15-29.

5. Ito K. Prostate cancer in Asian men. Nat Rev Urol. 2014;11:197-212.

6. Saini S. PSA and beyond: alternative prostate cancer biomarkers. Cell Oncol (Dordr). 2016 Apr;39(2):97-106

7. Singh P, Dogra PN, Gupta NP, Nayyar R, Seth A, Javali TD, Kumar R. Correlation between the preoperative serum prostate specific antigen, Gleason score, and clinical staging with pathological outcome following robot-assisted radical prostatectomy: an Indian experience. Indian J Cancer. 2011;48:483-7.

8. Catalona WJ, Partin AW, Sanda MG, Wei JT, Klee GG, Bangma CH, Slawin KM, Marks LS, Loeb S, Broyles DL, Shin SS, Cruz AB, Chan DW, Sokoll LJ, Roberts WL, van Schaik RH, Mizrahi IA. A multicenter study of [-2]pro-prostate specific antigen combined with prostate specific antigen and free prostate specific antigen for prostate cancer detection in the 2.0 to 10.0 $\mathrm{ng} / \mathrm{ml}$ prostate specific antigen range. J Urol. 2011;185(5):1650-5.

9. [Internet] Analytic Report. Results of National Census of Republic of Kazakhstan.2009.http://www.stat.gov.kz/getImg?id=WC16200032648

10. Bray F, Lortet-Tieulent J, Ferlay J, Forman D, Auvinen A. Prostate cancer incidence and mortality trends in 37 European countries: an overview. Eur J Cancer. 2010;46(17):3040-52.

11. Chen R, Huang Y, Cai X, Xie L, He D, Zhou L, Xu C, Gao X, Ren S, Wang F, Ma L,Wei Q, Yin C, Tian Y, Sun Z, Fu Q, Ding Q, Zheng J, Ye Z, Ye D, Xu D, Hou J, Xu K, Yuan J, Gao X, Liu C, Pan T, Sun Y; Chinese Prostate Cancer Consortium. Age-Specific Cutoff Value for the Application of Percent Free Prostate-Specific Antigen (PSA) in Chinese Men with Serum PSA Levels of 4.0-10.0 ng/ml. PLoS One. 2015;10(6):e0130308.

12. Ayagan B. History of Kazakhstan. Almaty, Kazakhstan: Atamura; 2013.

13. Geffré A, Concordet D, Braun JP, Trumel C. Reference Value Advisor: a new freeware set of macroinstructions to calculate reference intervals with Microsoft Excel. Vet Clin Pathol. 2011;40(1):107-12.

14. [Internet] American Cancer Society. What tests can detect prostate cancer early? http://www.cancer.org/cancer/prostatecancer/moreinformation/ prostatecancerearlydetection/prostate-cancer-early-detection-tests

15. Eckersberger E, Finkelstein J, Sadri H, Margreiter M, Taneja SS, Lepor H, Djavan B. Screening for Prostate Cancer: A Review of the ERSPC and PLCO Trials. Rev Urol. 2009; 11(3):127-33.

16. Nadler RB, Humphrey PA, Smith DS, Catalona WJ, Ratliff TL. Effect of inflammation and benign prostatic hyperplasia on elevated serum prostate specific antigen levels. J Urol. $1995 ; 154$ (2 Pt 1):407-13.

17. Barqawi AB, Golden BK, O'Donnell C, Brawer MK, Crawford ED. Observed effect of age and body mass index on total and complexed PSA: analysis from a national screening program. Urology. 2005;65(4):708-12

18. Wright JL, Lin DW, Stanford JL. The effect of demographic and clinical factors on the relationship between BMI and PSA levels. Prostate. 2011;71(15):1631-7.

19. Tchetgen $\mathrm{MB}$, Oesterling JE. The effect of prostatitis, urinary retention, ejaculation, and ambulation on the serum prostate-specific antigen concentration. Urol Clin North Am. 1997 ;24(2):283-291.

20. Bolduc S, Lacombe L, Naud A, Grégoire M, Fradet Y, Tremblay RR. Urinary PSA: a potential useful marker when serum PSA is between $2.5 \mathrm{ng} / \mathrm{mL}$ and 10 ng/mL. Can Urol Assoc J. 2007;1(4):377-81.

21. Pentyala S, Whyard T, Pentyala S, Muller J, Pfail J, Parmar S, Helguero CG, Khan S. Prostate cancer markers: An update. Biomed Rep. 2016;4(3):263-268.

22. Djavan B, Bursa B, Seitz C, Soeregi G, Remzi M, Basharkhah A, Wolfram R, Marberger M. Insulin-like growth factor 1 (IGF-1), IGF-1 density, and IGF-1/PSA ratio for prostate cancer detection. Urology. 1999;54(4):603-6.

23. Reis ST, Pontes-Júnior J, Antunes AA, Sousa-Canavez JM, Abe DK, Cruz JA, Dall'oglio MF, Crippa A, Passerotti CC, Ribeiro-Filho LA, Viana NI, Srougi M, Leite KR. Tgf- $\beta 1$ expression as a biomarker of poor prognosis in prostate cancer. Clinics (Sao Paulo). 2011;66(7):1143-7.

24. Dhir R, Vietmeier B, Arlotti J, Acquafondata M, Landsittel D, Masterson R, Getzenberg RH. Early identification of individuals with prostate cancer in negative biopsies. J Urol. 2004;171(4):1419-23.

25. Bu H, Bormann S, Schäfer G, Horninger W, Massoner P, Neeb A, Lakshmanan VK, Maddalo D, Nestl A, Sültmann H, Cato AC, Klocker H. The anterior gradient 2 (AGR2) gene is overexpressed in prostate cancer and may be useful as a urine sediment marker for prostate cancer detection. Prostate. 2011;71(6):575-87.

26. Nakanishi H, Groskopf J, Fritsche HA, Bhadkamkar V, Blase A, Kumar SV, Davis JW, Troncoso P, Rittenhouse H, Babaian RJ. PCA3 molecular urine assay correlates with prostate cancer tumor volume: implication in selecting candidates for active surveillance. J Urol. 2008;179(5):1804-9;

27. Llop E, Ferrer-Batallé M, Barrabés S, Guerrero PE, Ramírez M, Saldova R, Rudd PM, Aleixandre RN, Comet J, de Llorens R, Peracaula R. Improvement of Prostate Cancer Diagnosis by Detecting PSA Glycosylation-Specific Changes. Theranostics. 2016;6(8):1190-204.

28. Leidinger P, Hart M, Backes C, Rheinheimer S, Keck B, Wullich B, Keller A, Meese E. Differential blood-based diagnosis between benign prostatic hyperplasia and prostate cancer: miRNA as source for biomarkers independent of PSA level, Gleason score, or TNM status. Tumour Biol. 2016;37(8):10177-85 